\title{
Formação continuada para professores das escolas estaduais de Minas Gerais: A experiência dos Núcleos de Tecnologia Educacional
} \author{
Karina Letícia Júlio Pinto ${ }^{1}$, Daiane Padula Paz ${ }^{1}$, Gersica Agripino Alencar $^{2}$,
Josiane Carolina Soares Ramos \\ ${ }^{1}$ Instituto Federal de Educação, Ciência e Tecnologia do Rio Grande do Sul- campus \\ Porto Alegre \\ ${ }^{2}$ Universidade Federal Rural de Pernambuco \\ \{karina.leticia21@hotmail.com, daippaz@gmail.com, \\ geh.alencar@hotmail.com, josiane.ramos@poa.ifrs.edu.br\}
}

\begin{abstract}
The research sought to carry out a mapping of the continuing education courses offered by the 47 Educational Technology Centers - ETC Minas Gerais, for teachers of the state public network. Documentary research was used, through the analysis of the activity portfolios of the year 2015 of the ETC of the state of Minas Gerais. It has identified six courses offered (digital slate, proinfo projector, tablet, educational Linux, google apps and project security, ethics and citizenship on the internet) that are common among ETCs. Thus, as future activities, it is intended to conduct interviews with ETC coordinators to identify how actions are monitored, as well as the number of teachers trained by region.
\end{abstract}

Resumo. A pesquisa buscou realizar um mapeamento dos cursos de formação continuada ofertados pelos 47 Núcleos de Tecnologia Educacional- NTE mineiros, para professores da rede pública estadual. Utilizou-se da pesquisa documental, por meio da análise dos portfólios de atividade do ano de 2015 dos NTE do estado de Minas Gerais. Identificaram-se seis cursos ofertados (lousa digital, projetor proinfo, tablet, Linux educacional, google apps e projeto segurança, ética e cidadania na internet) que são comuns entre os NTE. Assim, como atividades futuras pretende-se realizar entrevista com coordenadores do NTE para identificar como é realizado o acompanhamento das ações, assim como a quantidade de professores capacitados por regional.

\section{Introdução}

Na última década cresceu a quantidade de iniciativas que utilizaram o termo "formação continuada" Gatti (2008); apesar de não haver um conceito exato do termo utilizado, é importante compreender em que circunstâncias está sendo utilizado. Assim, nesse estudo, utiliza-se "formação continuada" para referir-se à oferta de atividades que contribuam para o desempenho profissional, compreendendo cursos de formação de carga horária entre 4 e 8 horas, elaborados pelos NTE, de forma presencial e/ou a distância. A temática dos cursos é direcionada para fomentar a utilização dos recursos tecnológicos disponíveis nas escolas estaduais pelos professores. Tais cursos são aplicados na(s) escola(s) estadual(is) onde o professor trabalha ou na sede do NTE responsável por atender a região a qual pertence. Percebe-se que tanto a formação 
inicial como a formação continuada dos professores mantiveram relação direta com a realidade histórica de cada período, porém a base do discurso conservou-se até os dias atuais: a atualização e renovação do professor para enfrentar os desafios do ensino em meio às dificuldades cotidianas das escolas (GATTI, 2008).

O modelo de gestão gerencial, vivenciado no Brasil, principalmente nos anos noventa, e que hoje ainda persiste, atingiu a Educação de forma rude; trouxe o discurso que o professor deve ter competências para atuar e melhorar os resultados das avaliações externas, sendo ele o maior responsável pelo "sucesso" ou "fracasso" dos alunos. Segundo Freire (2002), é suspeita uma formação de educadores que seja alheia às condições sociais, culturais, econômicas das escolas e das famílias dos educandos. $\mathrm{O}$ professor é, sem dúvida, um profissional muito importante para o desenvolvimento da Educação, por isso a formação continuada pode ser bastante benéfica para o seu desenvolvimento pessoal e profissional.

Observa-se por meio da história da Informática na Educação no Brasil que desde o início houve propostas de formação para os professores (MORAES, 1997), porém ainda é atual a discussão sobre "o que" e "como" ensinar nos cursos de formação continuada voltados para as Tecnologias de Informação e Comunicação- TIC para os professores. Além disso, a terminologia "Informática na Educação" possui diversos sentidos que são identificados por meio do discurso do interlocutor, entretanto, é imprescindível que o conhecimento técnico (o saber manusear e trabalhar com as ferramentas hardware e software) e o conhecimento pedagógico (o saber utilizar as ferramentas de forma a fomentar o ensino- aprendizagem dos alunos) andem juntos, uma vez que são saberes que demandam dos professores uma busca permanente pela formação, pois "é pensando criticamente a prática de hoje ou de ontem que se pode melhorar a próxima prática" (FREIRE, 2002, p. 18).

\subsection{Núcleo de Tecnologia Educacional- NTE}

Nas últimas décadas houve importantes avanços na democratização da educação, assim como o desenvolvimento de ações que deram ênfase à formação inicial e continuada dos professores, contudo, observa-se que a organização e a aplicação das políticas educacionais de formação continuada voltadas para a utilização das TIC criadas apresentam muitos impasses para atingir os objetivos para o qual foram elaborados. Em 1997, foi criado o Programa Nacional de Informática na Educação- ProInfo, através da Portaria $\mathrm{n}^{\mathrm{o}} 522$, cuja finalidade inicial era promover o uso da tecnologia como instrumento de desenvolvimento pedagógico para o ensino público fundamental e médio. Para alcançar os objetivos almejados em 1997-1998, assim como a formação continuada dos professores, houve a implantação de Núcleos de Tecnologia Educacional- NTE em todas as Unidades Federadas- UF e do Centro de Experimentação em Tecnologia Educacional- CETE em Brasília.

Em 12 de dezembro de 2007, através do Decreto $n^{\circ}$ 6.300, o ProInfo passou a ser Programa Nacional de Tecnologia Educacional, objetivando oferecer o uso pedagógico das tecnologias de informação e comunicação nas redes públicas de educação básica. No mesmo ano já havia 418 NTE instalados no Brasil, distribuídos pelas regiões: Sudeste (148), Nordeste (96), Sul (83), Centro- Oeste (47) e Norte (44). Em Minas Gerais, segundo o Decreto Estadual n ${ }^{\circ} 45.849$, de 27 de dezembro de 2011, na estrutura organizacional da Secretaria de Estado de Educação- SEEMG os NTE desempenham suas atividades vinculados às Superintendências Regionais de Ensino- SRE sendo, 
ainda, subordinados à Subsecretaria de Informações e Tecnologias e à Superintendência de Tecnologias Educacionais, que se subdivide em três diretorias: Diretoria de Tecnologias Aplicadas à Educação- DTAE, Diretoria de Recursos Tecnológicos- DTEC e Diretoria de Apoio Operacional e Controle de Redes.

Em 2016, identificou-se a existência de 47 NTE em Minas Gerais (NTE Almenara, NTE Araçuaí, NTE Barbacena, NTE Campo Belo, NTE Carangola, NTE Caratinga, NTE Caxambu, NTE Conselheiro Lafaiete, NTE Coronel Fabriciano, NTE Curvelo, NTE Diamantina, NTE Divinópolis, NTE Governador Valadares, NTE Guanhães, NTE Itajubá, NTE Ituiutaba, NTE Janaúba, NTE Januária, NTE Juiz de Fora, NTE Leopoldina, NTE Manhuaçu, NTE Metropolitana A, NTE Metropolitana B, NTE Metropolitana C, NTE Monte Carmelo, NTE Montes Claros, NTE Muriaé, NTE Nova Era, NTE Ouro Preto, NTE Pará de Minas, NTE Paracatu, NTE Passos, NTE Patos de Minas, NTE Patrocínio, NTE Pirapora, NTE Poços de Caldas, NTE Ponte Nova, NTE Pouso Alegre, NTE São João Del Rey, NTE São Sebastião do Paraíso, NTE Sete Lagoas, NTE Teófilo Otoni, NTE Ubá, NTE Uberaba, NTE Uberlândia, NTE Unaí, NTE Varginha), realizando seus trabalhos junto a cada SRE, atuando em duas atividades principais: manutenção dos equipamentos de informática (Suporte Técnico) e realizando capacitação de servidores (professores, gestores, especialistas...) para a utilização das tecnologias no processo de ensino e aprendizagem (Suporte Pedagógico). O NTE realiza uma comunicação direta entre a escola (professores, gestores e alunos) e a utilização dos recursos tecnológicos disponibilizados (tablet educacional, lousa digital e computadores) objetivando impactos positivos no processo de ensino e aprendizagem.

\section{Metodologia}

Optou-se pela pesquisa documental, que de acordo com Gil (2008), é bem parecida com a pesquisa bibliográfica, porém na pesquisa documental os materiais coletados (portfólio, relatórios, documentos de instituições) ainda não receberam o tratamento analítico ou podem receber uma nova interpretação de acordo com os objetivos da pesquisa. Nesse caso, foram analisados 47 portfólios de atividades dos NTE mineiros do ano de 2015 (os portfólios de atividades de 2016 não estão incluídos nessa pesquisa porque ainda não estão disponíveis), buscando identificar os cursos de formação continuada ofertados aos professores das escolas estaduais de Minas Gerais.

Os 47 portfólios de atividades dos NTE do ano de 2015 estão disponíveis no sítio do Projeto Gestores NTE/Escolas (http://gnteescolas.educacao.mg.gov.br/documentos), o portfólio de atividades é o documento onde é apresentada todas as ações de cada NTE do estado, por meio dele é possível identificar as ações de suporte técnico (conserto de equipamento, manutenção de laboratórios de informática) e também as ações de suporte pedagógico (formação de professores, cursos ofertados).

\section{Resultados e discussões}

Dos quarenta e sete NTE, dois não possuíam portfólios disponíveis para a análise (NTE Manhuaçu e NTE São Sebastião do Paraíso) e não foi possível identificar em quatro NTE os cursos específicos ofertados (NTE Coronel Fabriciano, NTE Divinópolis, NTE Januária e NTE Leopoldina), pois os mesmos não reportam os cursos ofertados. Aos NTE que descrevem os cursos, foram encontrados seis cursos ofertados (Lousa Digital, Projetor Proinfo, Tablet, Linux Educacional, Google Apps e Projeto Segurança, Ética e Cidadania na Internet) que são comuns entre os NTE. 
VI Congresso Brasileiro de Informática na Educação (CBIE 2017)

Anais do XXIII Workshop de Informática na Escola (WIE 2017)

De acordo com a análise, o curso "Projeto Segurança, Ética e Cidadania na Internet" foi o mais ofertado durante o ano 2015, justifica-se pois foi um curso idealizado pela Secretaria de Estado de Educação- SEEMG e repassado para os NTE de forma que repassassem para professores e alunos. O curso da "Lousa Digital" foi o segundo mais ofertado.

É importante destacar que houve propostas regionais e diferenciadas, e que, no caso, foram incluídas na opção outros. No NTE Conselheiro Lafaiete e no NTE Ponte Nova identificou-se a execução de Projeto de formação de professores voltados para o uso das TIC com alunos que frequentam a sala de Atendimento Educacional Especializado- AEE (também conhecida como sala de Recursos Multifuncionais). O NTE Metropolitana B relatou a oferta de oficina sobre como produzir Histórias em Quadrinhos na sala de aula com o auxílio de programas educativos.

A troca de experiências e o conhecimento das pesquisas atuais referentes às Tecnologias da Informação e Comunicação- TIC na educação, também proporcionam a formação constante, assim é importante sinalizar o $4^{\circ}$ Seminário Jornada de Informática na Educação promovido pelo NTE Ituiutaba, com o objetivo de promover debates de temáticas como: robótica, relação dos professores com as tecnologias, gamificação e Linux Educacional e a participação de servidores do NTE Pouso Alegre no V Congresso Internacional de Tecnologia Educacional da ABT e o III Congresso Brasileiro de Recursos Digitais na Educação e o repasse dos aprendizados para servidores da SRE Pouso Alegre.

Nos dados relacionados à quantidade de servidores capacitados, notou-se que somente em nove portfólios a informação foi disponibilizada: NTE Almenara (1.055), NTE Caratinga (259), NTE Conselheiro Lafaiete (429), NTE Diamantina (145), NTE Guanhães (13), NTE Itajubá (201), NTE Monte Carmelo (177), NTE Patrocínio (603) e NTE Ubá (62). A formação continuada ofertada pelos NTE mineiros aos professores ainda é precária e muitos professores resistem em incorporar em suas aulas as novas tecnologias porque apontam a ausência de formação continuada um grande obstáculo (PINTO, SILVA, 2016). Em Portugal, no Instituto de Educação da Universidade de Lisboa, o professor Fernando Albuquerque Costa, juntamente com colaboradores elaborou o Projeto Escola Digital com a participação inicialmente de 53 professores, objetivando estimular e colaborar na utilização das TIC no dia a dia das escolas, enfatizando o professor como o agente transformador. $O$ que chama a atenção no projeto é que as entrevistas realizadas com educadores permitiram identificar percepções sobre "o que pensam" e "o que fazem" com as tecnologias e, a partir daí, elaborar uma proposta para se trabalhar na escola utilizando as TIC (COSTA et al., 2013). Outras pesquisas realizadas em cinco países europeus (Espanha, Grécia Holanda, Itália e Portugal) atribuíram a dimensão afetiva, um fator a considerar na elaboração da formação continuada (PERALTA, COSTA, 2007).

A dimensão afetiva, citada anteriormente, remete a "fatores relacionados com as percepções dos professores sobre as TIC, em geral e, em particular, com a sua utilidade e eficácia para a própria aprendizagem" (COSTA et al., 2013, p. 451). São fatores identificados como desafios para a utilização das TIC nas escolas, a falta de confiança dos professores e a conotação negativa em relação a tecnologia, o fato dos professores não se sentirem preparados para lidarem com as mudanças que as TIC implicam, as limitações da escola quanto a organização e disponibilidade dos recursos, pouco tempo 
VI Congresso Brasileiro de Informática na Educação (CBIE 2017)

Anais do XXIII Workshop de Informática na Escola (WIE 2017)

para planejamento, formação inadequada e insuficiente e falta de apoio (PERALTA, COSTA, 2007).

\section{Considerações finais}

O estudo identificou os cursos de formação continuada que são ofertados pelos NTE mineiros aos professores da rede pública. Para isso, realizou-se uma pesquisa documental aos 47 portfólios de atividades de 2015 dos NTE do estado de Minas Gerais. Notou-se seis cursos de formação continuada mais comuns entre os NTE (Lousa Digital, Projetor Proinfo, Tablet, Linux Educacional, Google Apps e o Projeto Segurança, Ética e Cidadania na Internet). Porém, não foram identificados a quantidade de servidores capacitados em todo o estado de Minas Gerais. Portanto, faz-se necessário maior acompanhamento e avaliação das propostas realizadas pelos NTE.

Assim, como atividades futuras, pretende-se identificar se as temáticas dos cursos dão conta dos anseios dos professores e se atendem à política de formação do estado.

\section{Referências}

Costa, F. A. et al. (2013) A caminho de uma escola digital. In: VII Conferência Internacional de TIC na Educação, 2013, Braga, Portugal.

Gatti, B. A. (2008) Análise das políticas públicas para formação continuada no Brasil, na última década. Revista Brasileira de Educação, v. 13, n. 37, p. 57-70.

Gil, A. C. (1999) Métodos e técnicas de pesquisa social. 5. ed. São Paulo: Atlas.

MEC. Ministério da Educação (2017) Relatório de Atividades 1996/2002 ProInfo. Disponível em $<$ http://www.proinfo.gov.br/upload/img/relatorio_died.pdf $>$ Janeiro.

Ministério da Educação (2017) Núcleo de Tecnologia Educacional: caracterização e critérios para Criação e Implantação. Disponível em https://www.fnde.gov.br/sigetec/upload/manuais/cat_crit_NTE.doc $>$ Janeiro.

Minas Gerais. Secretaria de Educação de Minas Gerais (2016) Disponível em: < https://www.educacao.mg.gov.br> Fevereiro.

Moraes, M. C. (1997) Informática Educativa no Brasil: uma história vivida, algumas lições aprendidas. Revista Brasileira de Informática na Educação, v. 1, n. 1, p. 19-44.

Peralta, H.; Costa, F. A. (2007) Competência e confiança dos professores no uso das TIC Síntese de um estudo internacional. Sísifo-Revista de Ciências da Educação, p. 77-86.

Pinto, K. L. J; Silva, J. M. C. (2016) Da visão do gestor a realidade do professor: uma análise da Formação Continuada referente as Novas Tecnologias em escolas estaduais de Minas Gerais. In: Anais do Workshop de Informática na Escola. 2016. p. 968.

Proinfo (2017) Disponível em <http://www.fnde.gov.br/programas/programa-nacionalde-tecnologiaeducacional-proinfo $>$ Janeiro. 